\section{Circumgrids: A repertory grid package for personal computers}

\section{WILLIAM V. CHAMBERS and JAMES W. GRICE Wright State University, Dayton, Ohio}

Personal construct theory (Kelly, 1955) is based on the assumption that a person's behavior is shaped by his/her constructs. Because of the importance placed on constructs, the major task for construct psychologists is the assessment of the individual's system of constructs. Nearly a thousand publications using construct theory have emerged since the theory's creation, with about $90 \%$ of these using scaling techniques called repertory grids. There are many forms of repertory grids (Beail, 1985; Fransella \& Bannister, 1977), with each providing some numeric or geometric representation of the individual's construct system. In completing a grid, the person typically rates or ranks a set of people or events along a number of construct dimensions, such as intelligent, friendly, and so forth. This rating/ranking produces matrices of numbers that are analyzed, per individual, by one or more of numerous types of analysis. Results from these separate analyses are then either interpreted per individual, as in clinical assessment, or concatenated with results from other subjects' grids to be further analyzed.

Research with grids can be very time-consuming when analysis proceeds by hand. For a number of years, the British government provided British researchers and clinicians free access to a principal components grid package. This service led to a dramatic increase in publications employing repertory grids. The service has since been discontinued. At present there are several commercially available computer packages for grid analysis. The packages generally provide only one type of analysis, are expensive, and require both programming skills and access to mainframe computers. The average researcher, clinician, or student hoping to use grid techniques today faces formidable obstacles. The purpose of this article is to introduce a computer grid package written for personal computers. The program, Circumgrids, is written in Turbo Pascal for the IBM PC system, is user friendly, and provides several types of analysis. The name Circumgrids is derived from the word circumspection, a technical term

The development of Circumgrids was supported by a grant from Wright State University. The authors' mailing address is: Department of Psychology, Wright State University, Dayton, OH 45431. in construct theory that essentially means viewing things from many angles. In the spirit of circumspection, Circumgrids was designed to provide the user access to several of the major methods for grid analysis.

Input. The Circumgrids package is menu driven. The user may enter data directly or interactively. Data is accepted in the form of dichotomous judgments and 7- or 13-point rating scales, as well as ranks. The type of scale used depends on the type of grid analysis chosen. The package accepts from 6 to 16 constructs and 6 to 16 elements.

Output. The user can choose among five different types of grid analysis: Fransella and Bannister's (1977) measures of intensity and consistency, Bieri's (1955) measure of cognitive complexity, Chambers's (1985a, 1985b) measures of logical consistency and integrative complexity, Landfield's (1977) measures of ordination, functional independence and polarization, Hinkle's (1965) measure of implications, and a principal components analysis (Slater, 1977). Most of the programs allow for an optional principal components analysis. Each of the programs prints to page the subject's grid, as well as scores, matrices, and plots that make up the particular analysis. No option exists for analyzing more than one grid.

Availability. A printout of the Pascal program is available, without charge, from the senior author. A disk copy of the program can be obtained by sending a double-sided, double-density 51/4-in. floppy disk in a returnable package.

\section{REFERENCES}

BEAlL, N. (1985). Repertory grid technique and personal constructs. Cambridge, MA: Brookline Books.

BIERI, J. (1955). Cognitive complexity-simplicity and predictive behavior. Journal of Abnormal \& Social Psychology, 51, 263-268.

Chambers, W. V. (1985a). A measure of the integrative complexity of personal constructs. Journal of Social \& Clinical Psychology, 3, 213-223.

Chambers, W. V. (1985b). A repertory grid measure of mandalas. Psychological Reports, 57, 923-928.

FRANSELLA, F., \& BANNISTER, D. (1977). A manual for repertory grid technique. London: Academic Press.

HINKLE, D. (1965). The change of personal constructs from the view point of a theory of construct implications. Unpublished doctoral dissertation, Ohio State University, Columbus, Ohio.

KELLY, G. A. (1955). The psychology of personal constructs. New York: Norton.

LANDFIELD, A. W. (1977). Nebraska symposium on motivation, 1976 Personal construct psychology. Lincoln: University of Nebraska Press. Slater, P. (1977). Dimensions of intrapersonal space. London: Wiley. 